\title{
US panel draws blank on Gulf War symptoms
}

Meredith Wadman, Washington

The fierce controversy over the origins of the chronic symptoms reported by US Gulf War veterans is set to continue. Last week, an expert committee at the Institute of Medicine (IOM) concluded it could not resolve the issue because there is not enough published evidence about the effects of exposure to suspect substances.

The committee based its opinion on a close reading of 1,000 papers from the scientific literature. These were almost all reports of occupational, clinical and terrorist exposure, rather than of Persian Gulf veteran exposure.

It concluded that the papers do not provide sufficient data to place blame with any certainty on the substances of most concern to veterans - the nerve gas sarin; pyridostigmine bromide (PB), a medicine troops took prophylactically to blunt the effects of nerve gas; depleted uranium from tanks and munitions destroyed in the war; and vaccines given to some troops to prevent anthrax and botulism.

"The bottom line is that we simply don't know enough to say whether there is a connection between exposure to these agents, or combinations of these agents, and specific health outcomes that remain long after the exposure," Harold Sox, who chaired the committee, told a news conference in Washington. Sox is professor of medicine at the Dartmouth-Hitchcock Medical Center in Lebanon, New Hampshire.

The committee said that a lack of information about actual troop exposures meant it had to review papers that did not involve Persian Gulf veterans. Even in this literature,

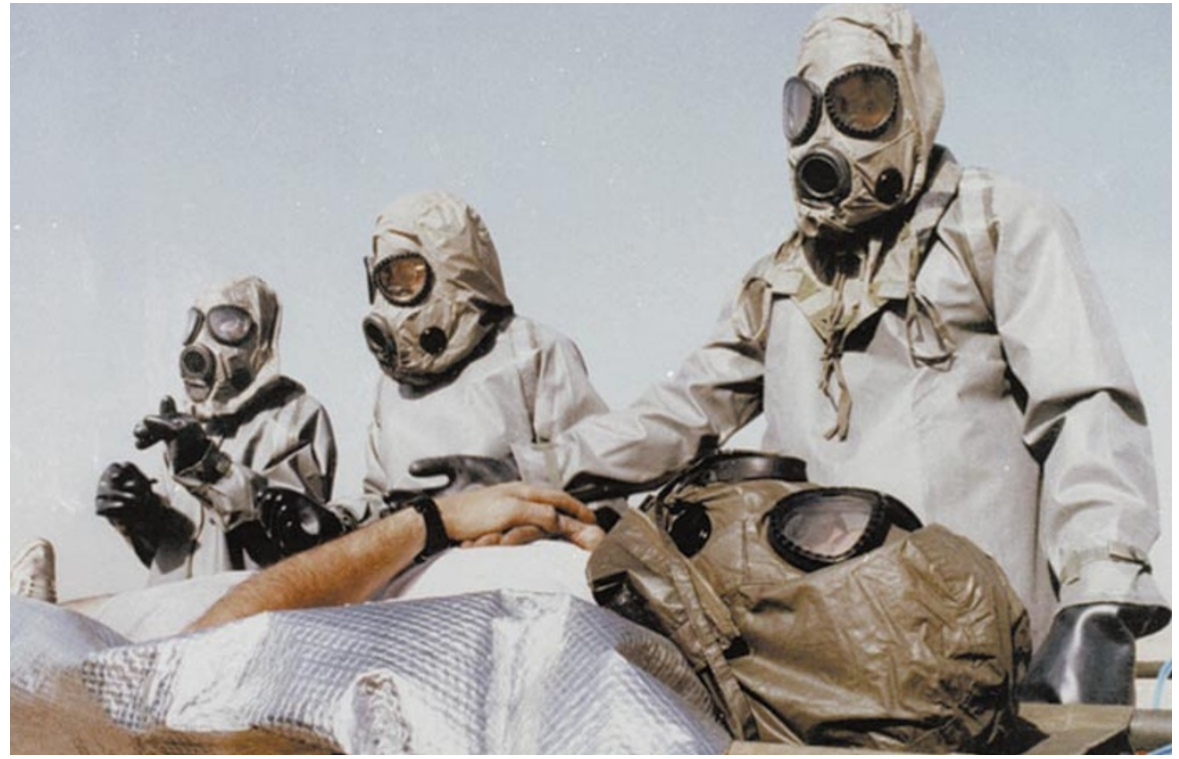

Chemical conundrum: too few data are available to establish the long-term effects of nerve gases.

insufficient information about the chronic effects of exposure made it impossible to draw conclusions in most instances.

There were some exceptions. The committee has now ruled out any role for depleted uranium in causing kidney disease or, in low doses, lung cancer. Conversely, three papers showed that neurological and psychological symptoms could persist for at least six months after exposure to sarin.

The committee also challenged several studies of Gulf War veterans by Robert Haley, director of epidemiology at the University of Texas Southwestern Medical Center in Dallas (see Nature 385, 187; 1997). These suggested that chronic neurological damage might be related to PB. But the IOM study noted methodological flaws in the studies, including heavy reliance on self-reporting, a small survey sample, and lack of a control group.

The IOM's report drew immediate criticism from activist veterans. They suggested that proof of links between their wartime exposure and current symptoms might lie in classified US Department of Defense information to which the committee did not have access. They also criticized the fact that the report did not consider exposure to combinations of agents, which they argued was a more likely battlefield scenario.

\section{Global warming threatens extinction for many species}

\section{David Spurgeon, Montreal}

Rapid rates of global warming will be bad news for biodiversity, particularly in the far north, according to a report prepared for the World Wildlife Fund and released recently in Toronto.

Jay Malcolm, of the University of Toronto's forestry faculty, and Adam Markham, of the non-governmental organization Clean Air-Cool Planet, based in Portsmouth, New Hampshire, warn that many species may be unable to migrate "away from increasingly less favourable climatic conditions to new areas that meet their physical, biological, and climatic needs".

The researchers used seven climate models and two vegetation models to analyse how fast species might have to move to keep up with projected warming.

High migration rates will be required over $38.3 \%$ of the land surface of Russia and $33.1 \%$ of Canada. The authors conclude that species living in the tundra and in coniferous forests "may be among the most vulnerable to global change".

In many countries, including Sweden, Finland and Iceland and several former Soviet republics, more than half of the existing habitat could be lost or changed into another habitat type. The same goes for seven of the twelve Canadian provinces. And in the United States, more than a third of existing habitat in eleven states could change.

Noting that even relatively optimistic predictions suggest that carbon dioxide concentrations are likely to have doubled by around the middle of this century and almost tripled by 2100 , the researchers suggest that species may need to move even faster than their findings indicate.
"If past fastest rates of migration are a good proxy for what can be attained in a warming world, then radical reductions in greenhouse gas emissions are urgently required in order to reduce the threat of biodiversity loss," the authors conclude.

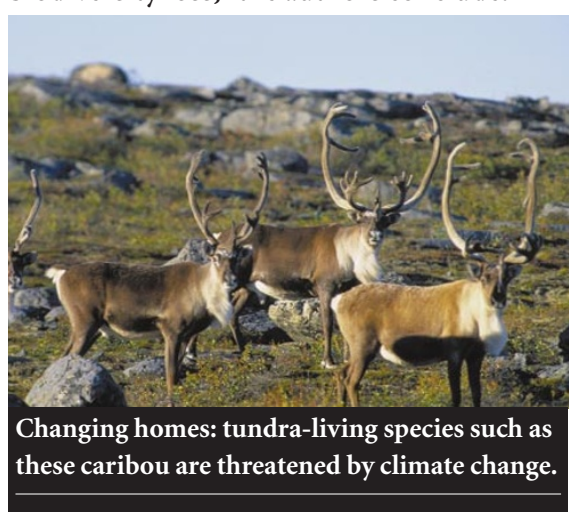

